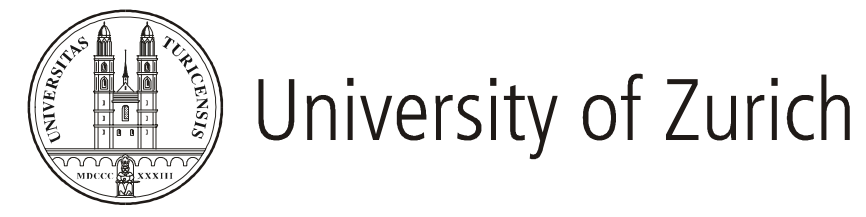

Socioeconomic Institute

Sozialökonomisches Seminar

Working Paper No. 0205

\title{
Lobbying Activities of Multinational Firms
}

Andreas Polk

June 2002 
Socioeconomic Institute

University of Zurich

Working Paper No. 0205

\section{LobBying ACtiVItIES OF MULtinational Firms}

June $2002,32 p$.

Author's address

Andreas Polk

Sozialökonomisches Seminar

Universität Zürich

Hottingerstrasse 10

$\mathrm{CH}-8032$ Zürich

Phone: +41-1-63439 49

E-mail: atpolk@soi.unizh.ch

Publisher

Sozialökonomisches Institut Bibliothek (Working Paper)

Rämistrasse 71

CH-8006 Zürich

Phone: +41-1-634 2137

Fax: +41-1-634 4982

URL: www.soi.unizh.ch

E-mail: soilib@soi.unizh.ch 


\title{
Lobbying Activities of Multinational Firms
}

\author{
Andreas Polk* \\ Socioeconomic Institute \\ University of Zurich
}

this Version:

June 20, 2002

\begin{abstract}
This paper investigates if multinationals influence the political process through lobbying more effectively than national firms. First, I introduce a model which contrasts a multinational's incentives for lobbying with those of a national firm. Then the effect of lobbying on the political decision is analyzed. I conclude that multinationals have smaller incentives to lobby because they have smaller stakes in national markets. But the effectiveness of lobbying by multinationals might be higher if the government cares much about production in the home country. The resulting regulation depends on the relative strength of these effects.
\end{abstract}

JEL: D72, F23, L51

Keywords: Multinational enterprizes, regulation, policy formation, lobbying, interest groups, foreign direct investment.

\footnotetext{
*Andreas Polk, Socioeconomic Institute, University of Zurich, Hottingerstrasse 10, 8032 Zurich, Switzerland, atpolk@soi.unizh.ch, www.soi.unizh.ch.

I am grateful to Armin Schmutzler, Lorenz Goette, Katrin Spitze and seminar participants at the University of Zurich for helpful comments.
} 


\section{Introduction}

Worldwide nominal in- and outflows of foreign direct investment grew from about 40-60 billions of US dollar in 1982 to about 1200 billion US dollar in 2000. The average growth rates of foreign direct investment are much higher than those of GDP or even trade (UNCTAD 2001, OECD 1999). Some authors argue that economic influence on the political process has grown due to this aspect of globalization (e.g. Reich (1993), Summers (1999)). This perception sometimes culminates in the notion of the 'loss of sovereignty' of the nation state. It reflects the idea that national governments lost most of their discretion to set policy, because the bargaining position of multinational companies vis a vis the government has improved. The reason is that firms relocate their production plants if governments set unwanted policies. As governments care about the presence of these firms, they must succumb to the wishes of the multinationals. A "race to the bottom" (Rauscher 1995) ensues.

and there is almost no discretion left to set national policy. ${ }^{1}$

The aim of this paper is to analyze differences in lobbying incentives between multinational and national firms, and show how they affect the political outcome. The paper attempts to address the following questions: How do lobbying incentives of multinationals differ from those of national firms? Will their influence be higher or smaller? What is the political outcome if multinationals are present: Will regulation be more lax? To answer these questions, the distinction between a national and a multinational firm needs to be clarified. Obviously, a multinational produces in at least two regions, in contrast to a national firm. But this distinction lacks precision: In principle, national firms may also relocate production abroad as a reaction towards rigid domestic regulation, and thus become a multinational. Accordingly, each national must be regarded as a potential multinational.

My approach takes Hirschman's famous distinction between "exit" and "voice" as mechanisms to react to adverse circumstances as a starting point (Hirschman 1970). I define a multinational as a firm which can relocate production with smaller moving costs than a national firm. To justify this view, consider a firm which intends to relocate production. A multinational possesses general skills and knowledge which are essential for operation in foreign countries. For instance, it possesses a network for cross-border communication, has knowledge how to handle cultural differences and is accustomed to foreign law. A national firm lacks such knowledge. In addition, if the multinational already runs a plant in the foreign country, expanding this plant will generally cause smaller costs than building a plant from scratch, which is necessary if a national

\footnotetext{
${ }^{1}$ Compare also Janeba (2000) and the quoted literature there.
} 
firm wants to move abroad. Hence "exit" as a reaction towards tight regulation induces smaller costs for multinationals than for national firms. In contrast "voice", namely the effort to reduce domestic regulation through lobbying, is equally available to both firms.

I will show that it is not obvious in such a setup that multinationals have more influence on the political process than national firms: On the one hand, a multinational might have smaller stakes in the home market. It can move at least a part of the production to a foreign country if the government sets unwanted regulation. The option to escape national regulation tends to reduce incentives to engage in lobbying activities against it. It should be expected that this effect leads to less political influence of multinationals. On the other hand, a government might be interested that multinationals produce at home. For instance, it might care about local production, the number of firms in the domestic market, or tax revenue. This aspect tends to improve the influence of multinational companies on national regulation. In sum, even though lobbying activities of multinationals might be less intense, they might also be more successful.

This paper contributes to the existing literature on lobbying in the presence of multinational firms. Several authors analyze the effect of foreign direct investment on the level of domestic protection. According to this view, investment activities soften adjustment costs induced through increased import penetration. The relocation of production facilities is a means to soften political pressures for increased protection. Not being cost reducing per se, direct investment serves as a "Quid Pro Quo" to reduce protection in the host country (compare for instance Bhagwati, Dinopoulos and Won (1987), Bhagwati, Dinopoulos and Wong (1992), or Grossman and Helpman (1996).) Other contributions analyze inward foreign investment flows as a reaction towards high protection in a country. If the protected industry is less concerned about competition through imports than competition through new investments, the possibility to relocate production as a response towards high protection restricts trade impeding measures. According to this view, foreign direct investment follows trade policy. It is economically efficient and restrains protective behavior of the host country. (Compare Blonigen and Ohno (1998), Ellingsen and Warneryd (1999). For a variation of this theme, Hillman and Ursprung (1999).). Although these two approaches differ with respect to the timing of the investment decision and the cost efficiency of relocation, they depart from the assumption that only domestic firms influence the political process.

To my best knowledge, there are only few approaches which allow also for lobbying of foreign firms. For instance, Konishi, Saggi and Weber (1999) extend the analyzes of Ellingsen and Warneryd (1999) and analyze foreign direct investment as a reaction towards high protection when foreign and domestic 
firms lobby a government. Olarreaga (1999) and Hillman and Ursprung (1993) regard the location structure as exogenously given and analyze the effect of a higher degree of foreign owned firms on domestic protection. In contrast to these latter approaches, in my approach the location structure is endogenously determined as a reaction towards tight regulation. Moreover, my approach has a different focus on the lobbying interest of foreign and domestic firms. The existing literature assumes divergent interests in trade policy between foreign and domestic firms. In contrast, my approach focuses on different incentives to engage in lobbying activities given that both types of firms prefer the same policy outcome, namely low regulation. Are multinational firms stronger than national firms in the political contest?

This paper is organized as follows: The first part (sections 2 and 3) derives differences in lobbying incentives between national and multinational firms. I employ a reduced form model of imperfect competition, which can easily be applied to specific market forms. The insights of the general model then work as a basis for the lobbying game in the second part (section 4). It investigates how firms determine contributions to the government, and derives the political outcome. Section 5 finally concludes.

\section{The basic set-up}

There are two countries ('home' and 'foreign'), which are separated by transportation costs $s$. Production in the home country is subject to real valued regulation $r>0$, which decreases variable profits. The producing firm is either a national firm or a multinational. Production in the foreign country is not subject to regulation. One might think of $r$ as a tax, environmental regulation, or a product standard which increases costs. ${ }^{2}$ The foreign country does not set any policy, independent of the home country's policy choice. The home country can thus be interpreted as being small. ${ }^{3}$

\footnotetext{
${ }^{2}$ Note that the type of regulation in this model does not influence the characteristics of the good. Goods produced at home and in the foreign country are homogenous, independent of the level of domestic regulation. The idea is that regulation does not serve as a means to differentiate domestic from foreign goods. This type of regulation applies for instance to environmental standards, which affect the way a good is produced, but not the good itself (i.e. water and air pollution, waste management, social security standards etc.). Other examples are competition policies affecting the degree of competition in a market (and hence profits), or tax policies. The model does not cover regulation policies which differentiate the good subject to regulation from others, as for instance laws which prohibit certain ingredients in food. Moreover, the model does not apply to regulation which affects production in both countries, as for instance general labor standards or tariffs.

${ }^{3}$ In this section I assume that regulation is exogenous. I will determine regulation endogenously in section 4 .
} 
I analyze the location decision of a multinational firm, which initially produces in the home country and serves the foreign country through exports. The firm can react to a change in national regulation via relocation: It can either stay in the home country and export to the other country, or it can relocate partially or completely to the foreign country. In the latter case, it serves the market of the home country through exports. Relocation has two effects on profits. First, variable profits change, because the marginal costs of production depend on national regulation and transportation costs. Second, total profits are affected, because the firm faces fixed moving costs if it relocates production.

I assume that the profits of the firm depend on the policy choice $r$, on transportation costs $s$ and on the location decision $l$. Markets are imperfect, and profit functions are given in reduced form. It is assumed that a unique solution to the product market game exists, with equilibrium quantities denoted as $q(r) .{ }^{4}$ Firm's profits can then be written in reduced form as

$$
\Pi=\Pi^{l}(r, s)-\delta F^{l} .
$$

The superscript $l \in\{n r, p r, c r\}$ denotes the location choice of the multinational firm. $n r$ means 'no relocation', $p r$ means 'partial relocation' and $c r$ means 'complete relocation'. Location structure $n r$ is the starting point of the analysis. The firm produces in the home country and serves the foreign market through exports. Parameter $\delta$ is a dummy, which is equal to one if the firm relocates (partially or completely). If it does not relocate, then no fixed costs arise and $\delta=0$. Note that the fixed moving costs $F^{l}$ are indexed as well. The model allows for different levels of these costs dependent on the choice of location.

To analyze differences in lobbying incentives between a national and a multinational firm, I consider the effect of a policy change on profits for two types of firms: (i) If the firm is a multinational, the location structure is an endogenous choice variable. The multinational might react to the policy choice through relocation. The location decision depends on transportation costs, the amount of regulation, and fixed moving costs. I will derive conditions in section 3 , such that the multinational takes advantage of this opportunity. (ii) If the firm is a national firm, it cannot relocate production. The location structure is given exogenously as $l=n r$ in this case. A national firm is restricted to produce in the home country and serve the foreign country through exports, irrespective of the amount of regulation $r$.

The following definition summarizes the approach:

\footnotetext{
${ }^{4}$ Since the model allows for international trade, the amount of goods consumed in the home country $q^{D}$ may differ from the amount of goods produced in the home country, $q^{S}$. This distinction will not be used in this section, but in section 4 .
} 
Definition 1 A national firm has location structure $l=n r$. Profits of a national firm are given by

$$
\Pi^{N A T}(r, s)=\Pi^{n r}(s, r) .
$$

A multinational firm chooses its location structure endogenously. Profits of the multinational are

$$
\Pi^{M N E}(r, s)=\max _{l}\left\{\Pi^{l}(s, r)-\delta F^{l}\right\} \quad, l \in\{n r, p r, c r\} .
$$

The idea that the national firm cannot move may appear overly restrictive. A national firm might also be able to relocate production and become a multinational, although at higher costs. The reasons for this assumption is tractability: If the national firm is also allowed to relocate production, the following arguments are still valid if moving costs of the national firm are higher than those of the multinational. The focus is on differences in profits between a multinational and a national firm, and the resulting differences in lobbying incentives. These exist whenever moving costs differ. Hence I normalize moving costs to be prohibitively high, such that the national firm will never relocate production, even though in principle it could.

Figure 1 illustrates an arbitrary profit function of the multinational, which is the upper bound of the profit functions for each location decision. The profit function of the national firm is given by $\Pi^{n r}$.

The aim is to derive some general principles on how multinational and national firms differ in their influence on the political process. The structure of the model is very general and does not rely on any specific form of competition at this stage. It entails only some general assumptions on the behavior and shape of the profit functions, which are satisfied in most models of competition.

The first assumption defines critical upper and lower bounds for transportation costs $s$ and the regulation parameter $r$. It serves to exclude some rather uninteresting cases: For instance, if transportation costs were allowed to be very high, both markets would be completely separated. Then it could never be the case that the multinational relocates completely and serves the domestic market through exports. Hence, either the multinational produces in the home country; then there is no difference between the national and the multinational firm. Or the multinational produces abroad; but then national regulation does not affect it at all, because markets are completely separated. To exclude this uninteresting case, transportation costs are bounded above, and it is always possible to serve a market through exports.

The regulation parameter is also bounded above. Regulation increases the cost of production. Thus very strict regulation can lead to negative variable profits 


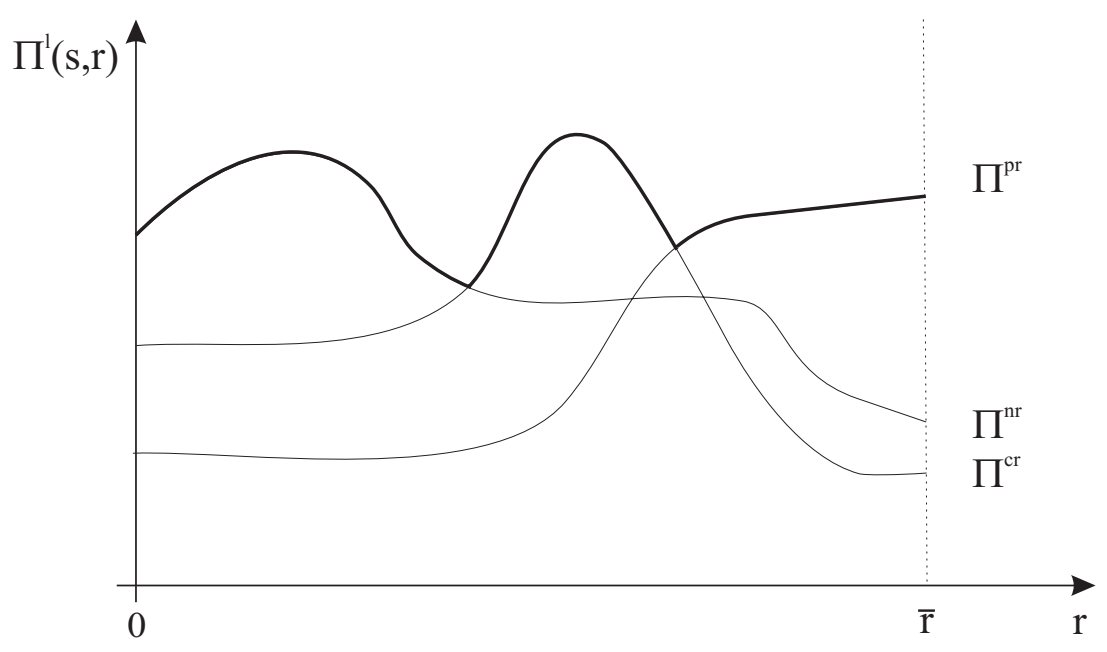

Figure 1: Profits of the multinational depend on the location decision $l \in$ $\{n r, p r, c r\}$. It is the upper bound of national firm's profits (printed in boldface).

of the national firm. To exclude this case, I restrict the parameter range or $r$. Regulation will never drive the national firm out of the market. ${ }^{5}$ Note that the upper bound for $r$ may depend on the exogenous parameter $\mathrm{s}$, that is $\bar{r}=r(s)$. The same applies for $\bar{s}$, which may be a function of the realized level of regulation, $\bar{s}=s(r)$ :

Assumption 1 a) Upper bounds for $r$ and $s$ exist: Variable profits are negative for any value of $s$, if $r>\bar{r}$. Markets are completely separated by transportation costs for any value of $r$, if $s>\bar{s}$.

b) The government sets regulation, such that profits are positive if production takes place in the home country: $r \in[0, \bar{r}]$.

Transportation costs do not separate the markets completely, and both countries can be served through exports: $s \in[0, \bar{s}]$.

The next two assumptions state how regulation affects profits in the home country. Regulation decreases profits if the firm produces at least partly in the home country. This is a rather intuitive assumption and is satisfied for most forms of competition. ${ }^{6}$ If production takes place in the foreign country

\footnotetext{
${ }^{5}$ This implies that the multinational is not driven out of the market either, because it can always perform at least as good as the national firm.

${ }^{6} \mathrm{~A}$ contrary view for the special case of environmental regulation is given by Porter (1991)
} 
only, regulation in the home country may increase or decrease profits of the multinational. The effect is ambiguous and depends on the specific form of competition. For instance, I allow for circumstances where firms benefit from raising rivals' costs, as is the case in the application to Cournot competition discussed in section $3.2 .^{7}$

Assumption 2 If a firm produces at least partly in the home country, regulation decreases profits: $\frac{\partial \Pi^{l}(s, r)}{\partial r}<0$, if $l \in\{n r, p r\}$. If the multinational does not produce in the home country, regulation affects its profits monotonically.

Since regulation affects only domestic production, but not production abroad, it is intuitive to assume that regulation has a higher impact if more production takes place in the home country. Note that the assumption allows that profits depend positively on regulation if the multinational produces solely in the foreign country. I make the following assumption on the impact of regulation on profits: ${ }^{8}$

Assumption 3 There is a positive relationship between the extent of production in the home country and the effect of regulation on profits, that is

$$
\frac{\partial \Pi^{n r}(r, s)}{\partial r} \leq \frac{\partial \Pi^{p r}(r, s)}{\partial r} \leq \frac{\partial \Pi^{c r}(r, s)}{\partial r}
$$

Moving costs depend on the location structure in the following sense:

Assumption 4 Moving costs depend on the type of relocation: If the firm relocates completely to the foreign country, fixed moving costs are higher than with partial relocation, i.e. $F^{c r} \geq F^{p r}$. With no relocation, $\delta=0$, otherwise $\delta=1$.

Assumption 4 is a 'monotonicity assumption' on the amount of fixed moving costs, which assures that each location structure is optimal for a specific parameter range. If this assumption did not hold and $F^{c r}<F^{p r}$, it would never be optimal to relocate partially: Suppose that regulation is low and production in the home country is optimal. If regulation increases such that it becomes

and Porter and van der Linde (1995). However, their argument relies on some specific conditions and cannot be sustained for environmental regulation in general (Schmutzler 2001).

${ }^{7}$ In a basic model of Cournot competition, profits of the multinational increase if the competitor in the home market faces higher variable costs through regulation.

${ }^{8}$ Note that this assumption can be written in a more intuitive, but slightly less precise way as $\left|\frac{\partial \Pi^{n r}(r, s)}{\partial r}\right| \geq\left|\frac{\partial \Pi^{p r}(r, s)}{\partial r}\right| \geq\left|\frac{\partial \Pi^{c r}(r, s)}{\partial r}\right|$. 

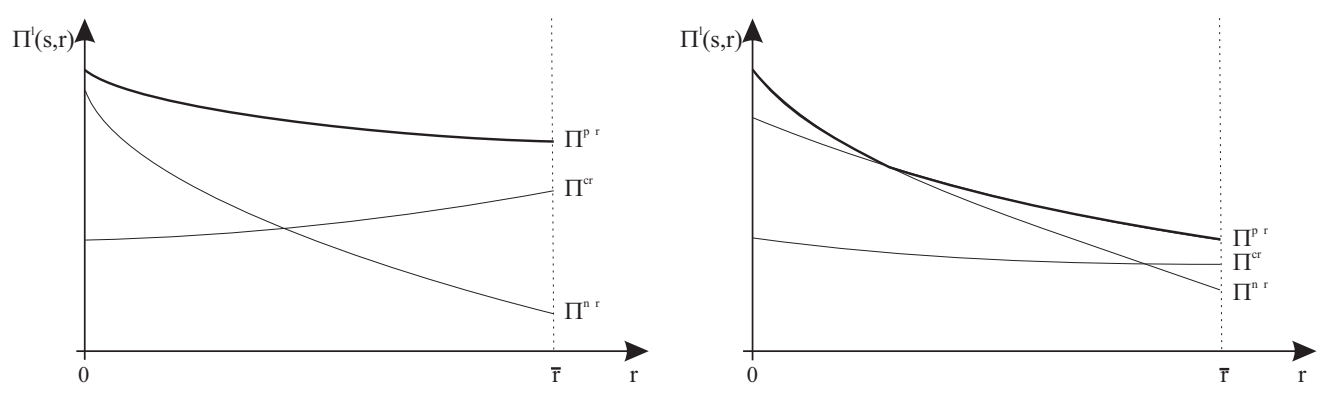

Figure 2: Possible profit functions of the national and the multinational firm satisfying assumptions 1 to 4 .

optimal to relocate, partial relocation is no option. The reason is that partial relocation has two negative effects compared to complete relocation: First, the firm escapes national regulation only partly, which leads leads to lower variable profits compared to complete relocation. Second, fixed moving costs are higher. However, transportation costs could be saved. But since it was optimal to bear transportation costs in the first place with slightly lower regulation, transportation costs cannot be the sole reason to relocate partially. ${ }^{9}$

Figure 2 provides examples on how the profit functions of the multinational and the national firm might look like.

I will denote the loss of profits through regulation as the 'stakes' of a firm in the home market. The stakes of a firm define possible benefits through lobbying. If the multinational has smaller stakes in the home market than a national firm, regulation affects the firm to a smaller extent. Other things equal, this should result in a smaller interest for the multinational to engage in costly lobbying.

The following definition states the idea of smaller stakes in the home market formally. In the remainder of the paper, I will use the following notation: $\Delta \equiv$ $r-r^{0}$ is the change in regulation from $r^{0}$ to $r, \Delta \Pi^{M N E}(r, s, \Delta) \equiv \Pi^{M N E}(r, s)-$ $\Pi^{M N E}(r-\Delta, s)$ denotes the corresponding profit change of the multinational firm, and $\Delta \Pi^{N A T}(r, s, \Delta) \equiv \Pi^{N A T}(r, s)-\Pi^{N A T}(r-\Delta, s)$ for the national. Note that if $r>r^{0}, \Delta \Pi^{N A T}(r, s, \Delta)<0$, but $\Delta \Pi^{M N E}(r, s, \Delta) \gtrless 0$ by assumptions 2 and $3 .^{10}$

\footnotetext{
${ }^{9}$ Note that profits decrease continuously in regulation by assumption 2. Moreover, they decrease faster with partial relocation by assumption 3 .

${ }^{10}$ Note that $\Pi^{M N E}(r, s)$ denotes the profits of the multinational which result from the maximization problem over the location decision.
} 
Definition 2 For a given level of transportation costs $s$, the multinational company has smaller stakes in the home country compared to a national firm, if and only if

$$
\left|\Delta \Pi^{M N E}(r, s, \Delta)\right| \leq\left|\Delta \Pi^{N A T}(r, s, \Delta)\right| \text { for all } r, \Delta
$$

and

$$
\left|\Delta \Pi^{M N E}(r, s, \Delta)\right|<\left|\Delta \Pi^{N A T}(r, s, \Delta)\right| \text { for at least one pair of } r, \Delta \text {. }
$$

\section{The interest of MNEs in national policies}

\subsection{A general model}

To analyze differences in lobbying between a multinational and a national firm, incentives to lobby need to be distinguished from the impact of lobbying on the policy decision. This section focusses on the incentives to influence political decisions. I show that multinational companies have different stakes in domestic regulation than national firms. The result of this section will then be used in section 4 , which focusses on the effectiveness of lobbying.

Whether a multinational has smaller stakes in the home market than a national firm depends on the relationship of the exogenous parameters for transportation costs $s$, regulation $r$ and fixed moving costs $F^{l}$. When the multinational decides if to relocate production, it has to take different aspects into account. First, if it relocates, fixed moving costs reduce profits. On the other hand, relocation serves to escape national regulation, and profits decline to a smaller extent. Therefore the relation between fixed moving costs and the change in variable profits through regulation is essential for the decision to relocate production. Second, if the multinational relocates, variable costs change because transportation costs become more or less important. For instance, if the multinational relocates partially, transportation costs become less important. If it relocates completely, the importance of transportation costs increases.

To illustrate these aspects, take the initial location structure as a starting point. The multinational produces in the home country only. If it relocates partially, it saves transportation costs, because the foreign market tends to be served by local production. The gain from relocation is two-fold: The firm escapes national regulation and saves transportation costs. Next, suppose the firm is present in both markets. When it decides if to relocate completely, it has to bear increased transportation costs to serve the home market, which cannot be served by local production anymore. Therefore, the gain is to escape 
national regulation, but only at the cost of higher fixed and transportation costs.

The optimal location decision is determined by the amount of fixed costs which have to be paid for relocation, given specific values of transportation costs and regulation. ${ }^{11}$ The following proposition specifies this:

Proposition 1 Suppose the following conditions are satisfied:

(i) $F^{p r}<\Pi^{p r}(\bar{r}, s)-\Pi^{n r}(\bar{r}, s)$ or

$$
F^{c r}<\Pi^{c r}(\bar{r}, s)-\Pi^{n r}(\bar{r}, s) .
$$

(ii) $F^{p r}>\Pi^{p r}(0, s)-\Pi^{n r}(0, s)$.

The multinational has the same stakes in the home market compared to a national firm if regulation is lax (i.e. for small $r$ ). If the regulation gets tighter and reaches a critical level, the multinational has smaller stakes in the home market than a national firm.

Proof. The proof is given in the appendix.

The multinational has the same stakes as a national firm if it produces in the home country only. This is the case if it is optimal to produce at home with the smallest possible regulation. If this was not the case, it would never be optimal to produce in the home country only, because variable profits decline in $r$. Condition (ii) of the proposition states the respective condition: If, for the smallest level of regulation, the difference in profits between partial relocation and no relocation is smaller than the amount of necessary fixed costs to relocate partially, it is not profitable to relocate production. Complete production in the home country is the best location structure in this case.

If regulation becomes tighter, the multinational must have an incentive to move abroad. If this is not the case, differences between multinational and national companies do not exist. We must assure that the multinational has an incentive to relocate production either partially or completely for some regulation parameter $r$. It suffices to consider the upper bound $\bar{r}$, because variable profits decline in $r$. Condition (i) states these requirements: Fixed costs for either partial or complete relocation must be less than the difference in profits between some type of relocation and production at home, if regulation is strictest. These conditions are sufficient, because profits are continuous and declining in $r$ if production takes at least partially place in the home country (assumption 2 and 3). An interval of regulation exists, which induces relocation of the multinational. The national firm cannot move by definition.

\footnotetext{
${ }^{11}$ Figure 2 shows that fixed costs shift the profit functions vertically. Their value is essential for the determination of the optimal location structure.
} 
As a result, both firms face different profits with high regulation, if condition (i) of proposition 1 applies.

Note that we are not primarily interested in the difference in profits, but in different stakes between the national and the multinational firm. The term 'stakes' accrues to a change in profits due to a change in regulation, not to the height of profits per se (compare definition 2). Proposition 1 implies that the multinational has higher profits than the national firm if regulation is tight, and that there is no difference in profits if regulation is lax. Trivially, the latter case implies that both types of firms have the same stakes in the home market if regulation is low. If profits are identical, both firms have the same stakes. However, condition (i) alone does not imply that the multinational has smaller stakes in the home market if regulation is high. It only implies that profits are different; but even though the amount of profits is different, the stakes of both firms may be the same if they are affected through a change in regulation in the same way.

It is assumptions 2 and 3 which assure that different profits lead to different stakes. Unequal profits result from different location structures. Assumption 2 implies that profits decrease in regulation if the firm produces in the home country. This assumption alone is not sufficient to induce different stakes between the firms. Assumption 3 assures that the extent of regulation on profits increases if more production takes place at home. The combination of these two assumptions leads to the result of proposition 1. Figure 3 illustrates it graphically. ${ }^{12}$

If the general model is applied to specific forms of competition, proposition 1 gives upper and lower bounds for fixed moving costs, which depend on transportation costs and regulation. If moving costs are above the upper bound, relocation is no means to escape regulation. The cost of moving abroad exceeds its benefits, which is less impact of regulation and possibly lower transportation costs. In this case no differences between a multinational and a national firm exist.

The following corollary contrasts this to the case where the multinational has always smaller stakes in the home market, independent of the regulation in place. Intuitively, this is the case if moving costs are small relative to possible gains of relocation. Corollary 1 gives conditions only on the upper bound of fixed costs. The intuition is analogous to the one of proposition 1. I simply state the result, the left part of figure 2 plots a corresponding situation. Note that a condition similar to condition (i) of the previous proposition is not necessary. Profits decline faster in regulation if more production takes place

\footnotetext{
${ }^{12}$ Note that the argument does not rely on the type of relocation (partially or completely). The relevant condition is that production moves at all.
} 

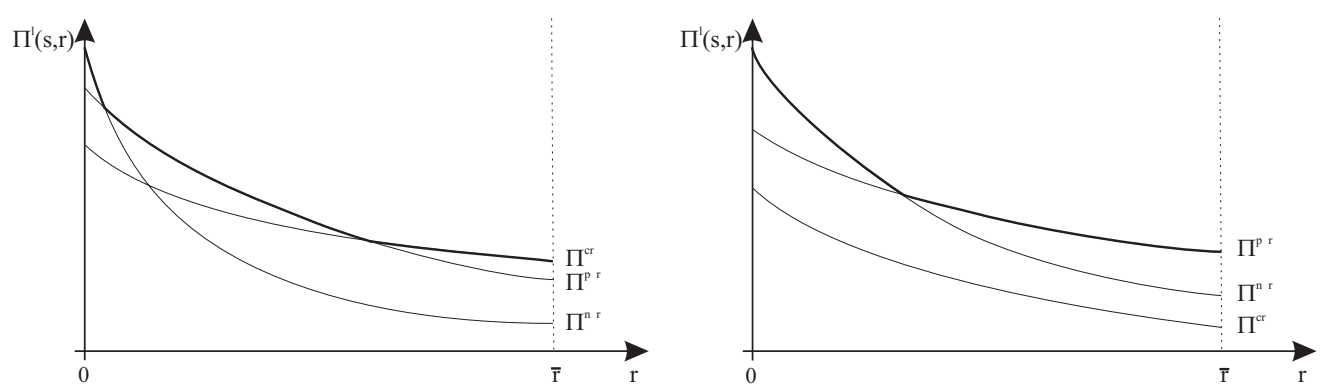

Figure 3: A national and multinational firm have different stakes in regulation if regulation is high. If it is low, both firms have the same stakes. The multinational completely relocates if regulation is strict and fixed costs are small. In this case transportation costs tend to be small, such that complete relocation becomes an option if regulation is sufficiently high (left). If fixed costs for complete relocation are high, or transportation costs play an important role, complete relocation is never optimal (right).

in the home country. The stated condition thus also implies condition (i) of proposition 1.

Corollary 1 Suppose the following condition is satisfied:

$$
F^{p r}<\Pi^{p r}(0, s)-\Pi^{n r}(0, s) .
$$

The multinational has smaller stakes in the home market compared to a national firm, independent of the regulation $r$.

Proof. Follows immediately from the proof of proposition 1.

\subsection{An application to Cournot competition}

This section applies the general model to a basic two-stage game. Firms play Cournot competition and face linear demand. The regulation is an input tax $t$ which increases marginal costs. In the first stage, the multinational chooses a location structure for a given tax, as described in the previous section. In the second stage, firms play Cournot competition. The game is solved by backwards induction.

The notation is as follows: There are two countries $k \in\{$ home, foreign $\}$, and two firms $\mathrm{X}$ and $\mathrm{Y}$ which produce a homogeneous good consumed in both 
countries. The amount of the good produced by firm X (Y) and consumed in country $k$ is denoted by $x^{k}\left(y^{k}\right)$. Consumers in each country have linear demand $p^{k}=a-x^{k}-y^{k}$, where $p$ denotes the price of the good and $a$ is a market parameter. Firm Y produces in the foreign country. It is inactive and cannot relocate in the first stage of the game. ${ }^{13}$ The analysis focuses on firm $\mathrm{X}$, which is initially located in the home country. It can relocate production if it is a multinational, and can not do so if it is a national firm.

The cost structures of both firms consist of two parts: There are constant marginal costs, which consist of production costs $m$, transportation costs $s$ if the firm exports to the other country, and the input tax $t$ of firm $\mathrm{X}$ if it produces at home. Plant specific fixed costs $F$ arise if the multinational moves production. For simplicity, I assume that $F \equiv F^{p r}=F^{c r}$. If part of the production takes place in the foreign country, the multinational is able to move production completely without further costs.

Standard calculations yield firm X's variable profits for a given tax in the home country, and for each possible location structure: ${ }^{14}$ With two firms having constant marginal costs $c_{x}$ and $c_{y}$, and linear demand with slope -1 , standard derivations show that the multinational sells $x^{k}=\frac{1}{3}\left(a-2 c_{x}^{k}+c_{y}^{k}\right)$, and firm Y sells $y^{k}=\frac{1}{3}\left(a-2 c_{y}^{k}+c_{x}^{k}\right)$ in each market. Variable profits in each market are $\Pi_{x}^{k}=\frac{1}{9}\left(a-2 c_{x}^{k}+c_{y}^{k}\right)^{2}$ and $\Pi_{y}^{k}=\frac{1}{9}\left(a-2 c_{y}^{k}+c_{x}^{k}\right)^{2}$ respectively. Straightforward application and accounting for fixed costs yields the relevant profit functions for each location structure. ${ }^{15}$

Proposition 2 Suppose the following conditions are satisfied:

(i) $s \geq 0 ; t \geq 0$,

(ii) $\quad a-m \geq 2(s+t)$,

(iii) $F \in\left[\frac{4}{9}(a-m-s) ; \frac{1}{9}(a-m)^{2}\right]$.

A multinational and a national firm have the same stakes in the home market if the tax is small. If the tax reaches a critical level, a multinational firm has smaller stakes in the home market.

Proof. The proof is given in the appendix.

The conditions of this proposition result from assumptions 1 to 4, and from application of proposition 1 :

\footnotetext{
${ }^{13}$ Firm Y can be interpreted as the rest of the market.

${ }^{14}$ Compare for instance Tirole (1988, Chapt. 5.4).

${ }^{15} \Pi^{n r}(s, t)=\frac{1}{9}\left[(a-m+s-2 t)^{2}+(a-m-2 s-2 t)^{2}\right]$,

$\Pi^{p r}(s, t)=\frac{1}{9}\left[(a-m+s-2 t)^{2}+(a-m)^{2}\right]-F$,

$\Pi^{c r}(s, t)=\frac{1}{9}\left[(a-m-s)^{2}+(a-m)^{2}\right]-F$.
} 
Fixed costs for relocation are independent of the location structure, therefore assumption 4 is trivially satisfied. Assumption 1 requests that upper and lower bounds for $s$ and $t$ exist, such that all markets are served for parameters within this range. Conditions (i) and (ii) of proposition 2 define these bounds. Note that the upper bounds of $s$ and $t$ depend on each other. The highest possible tax rate depends on the height of transportation costs and vice versa. These conditions imply $\bar{s}(t)=(a-m) / 2-t, \bar{t}(s)=(a-m) / 2-s$. Assumptions 2 and 3 are then satisfied as well, as is shown in the appendix. The conditions of proposition 1 are satisfied if and only if $F$ lies within the stated parameter range. Therefore, the general result of proposition 1 holds, and the result follows. ${ }^{16}$

One particular shape for the profit functions is given in figure 3 above. This is not the only possible shape. Three different cases might arise, depending of the values of $s$ and $t$. To distinguish these, I define $s^{*}$ as a critical level of transportation costs. If $s>s^{*}$, the multinational will never relocate completely to the foreign country. The critical level of transportation costs results from the condition $\Pi^{p r}(s, \bar{t})=\Pi^{c r}(s, \bar{t})$, which defines $s^{*}$. It states that profits under complete relocation are the same as profits with partial relocation, given that the tax level reaches its maximum level $\bar{t}$. In this case, the multinational will never relocate completely. Even if regulation takes its maximum value, profits with partial relocation are at least as high as profits with complete relocation. ${ }^{17}$ We get from the above condition

$$
s^{*} \equiv \frac{1}{4}(a-m)
$$

The following values of the tax parameter will be used in corollary 2. They define critical levels of transportation costs, such that the multinational is indifferent between no relocation and partial relocation $\left(t^{1}\right)$, and partial relocation and complete relocation $\left(t^{2}\right)$. These values depend on transportation costs and moving costs. $t^{1}$ results from the condition $\Pi^{n r}(s, t)=\Pi^{p r}(s, t)$, and $t^{2}$ from $\Pi^{p r}(s, t)=\Pi^{c r}(s, t)$ :

$$
\begin{aligned}
t^{1} & \equiv \frac{1}{2}\left[(a-m-2 s)-\sqrt{\left.(a-m)^{2}-9 F\right]},\right. \\
t^{2} & \equiv \frac{1}{2}\left(a-m-\frac{1}{2} s\right)+\sqrt{\frac{1}{4}\left[(a-m)^{2}-s(a-m)+\frac{1}{4} s\right]-4 s^{2}-\frac{9}{8} F .}
\end{aligned}
$$

The following corollary gives the explicit solutions of this Cournot model:

\footnotetext{
${ }^{16}$ For derivations of the relevant parameter ranges consult the proof in the appendix.

${ }^{17}$ Note that markets are not separated completely if $s>s^{*}$, because partial relocation may be optimal.
} 
Corollary 2 Suppose that the conditions of proposition 2 are satisfied. It is possible to distinguish three cases.

The multinational does not relocate completely if transportation costs are high $\left(s>s^{*}\right)$. It produces in the home country and exports to the foreign country if taxes are low $\left(t \leq t^{1}\right)$. If taxes are high $\left(t>t^{1}\right)$, the multinational relocates partly and serves both markets through local production.

If transportation costs are small $\left(s<s^{*}\right)$, but $s>t^{1}$, three different location structure arise:

- The multinational does not relocate if $t<t^{1}<s$.

- The multinational relocates partly if $t^{1}<t<s$.

- The multinational relocates completely if $t^{1}<s<t$.

If transportation costs are low $\left(s<s^{*}\right)$, and $s<t^{1}$, the multinational will never produce in both countries:

- The multinational does not relocate if $t<t^{2}$.

- The multinational relocates completely if $t>t^{2}$.

Proof. The proof is given in the appendix.

The intuition corresponds to the former section. For a graphical illustration compare figure 3: The right hand side illustrates the case of high transportation costs $\left(s>s^{*}\right)$. It never pays to relocate completely, even if regulation is very high. The left hand side illustrates the case of low transportation costs $\left(t^{1}<s<s^{*}\right)$. If pays to relocate partially if regulation is intermediate. If it is sufficiently high, complete relocation is the best choice.

Figure 4 shows how the relocation decision depends on transportation costs, fixed costs and taxes. Note that fixed costs influence the critical tax levels $t^{1}$ and $t^{2}$.

Note that the decision between partial and complete relocation depends on the comparison of transportation costs and taxes. It is independent of moving costs, because partial and complete relocation induce the same amount of fixed costs. It never pays to relocate completely to the foreign country if transportation costs are high, because tax savings cannot compensate for transportation costs. If the tax reaches a critical level such that relocation becomes optimal, the multinational considers whether to relocate completely or partly in this case. This decision depends solely on the trade-off between tax savings through complete relocation and higher transportation costs. If 


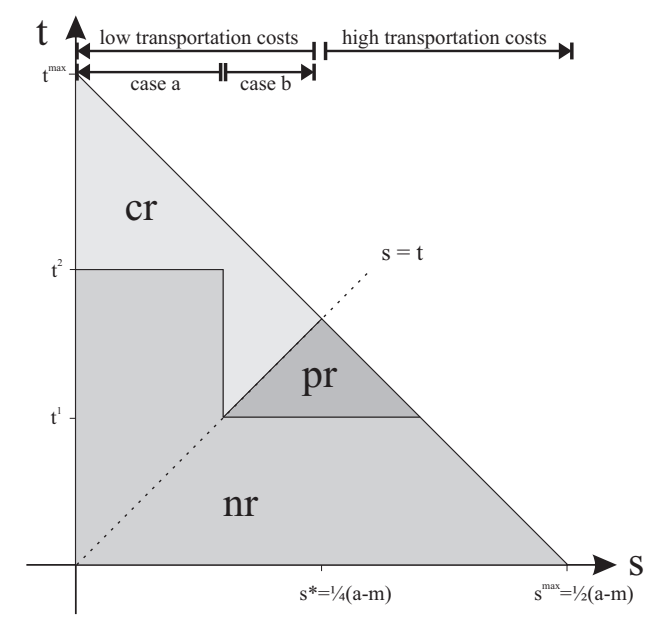

Figure 4: Optimal location decisions of a national firm in the Cournot example. The location decision depends on transportation costs $s$ and taxes $t$, and fixed costs.

transportation costs are high, tax savings are too small to induce complete relocation. This is the case even if tax payments take on their highest possible value. $^{18}$

If transportation costs are low, two cases may arise: complete immediate relocation $\left(s<t^{1}\right)$, and partial relocation first $\left(s>t^{1}\right)$. In both cases it is optimal to relocate completely if the tax is sufficiently high. High tax savings dominate transportation costs. The question remains whether the multinational should relocate completely once the tax reaches a critical level. This decision depends on the amount of moving costs: The critical tax level $t^{1}$ decreases if moving costs are low. Hence lower fixed costs imply that the multinational reacts faster towards a tax increase. If $s>t^{1}$, moving costs and the critical tax level which induces relocation are small. Transportation costs are high enough such that it pays to move only partially. In such a situation, it is better to face moving costs than to pay taxes, but it is also better to pay taxes than to pay transportation costs. Only if the tax rises further, complete relocation becomes optimal. If $s<t^{1}$, transportation costs are small enough such that complete relocation is optimal once the trade-off between fixed costs and lower taxes induces relocation. Hence transportation costs are too small to play any role in the decision between complete and partial relocation. Relocation reduces to the decision between fixed costs and tax payments, if transportation

\footnotetext{
${ }^{18}$ Remember that the upper bound of $t$ depends negatively on transportation costs.
} 
costs are low.

In sum, multinational enterprizes have smaller stakes in the home country than national firms, if certain conditions are met. Low transportation costs and low costs of relocation make this difference more likely. Regulation becomes more important and the multinational can easily relocate production, which leads to different stakes of both types of firms. This argument contrasts with the perception that multinationals have a higher influence on the political process than national firms. In contrast, it indicates that multinationals have smaller stakes in the home country. They care less about national regulation, which tends to decrease lobbying incentives. But if multinationals do not care about national politics, perhaps it is politicians who care about multinationals?

\section{The lobbying game}

This section focuses on the effectiveness of lobbying. It takes the results of the previous section as a starting point. Multinationals have smaller stakes in the home market, which tends to decrease lobbying incentives. But incentives to engage in lobbying depend on its effectiveness. Multinationals might be more effective in lobbying, compared to national firms. If this is the case, higher effectiveness might compensate for lower stakes, which leads to more influence.

There are several possible reasons why politicians care more about multinationals than about national firms. For instance, multinationals are quite important as employers. People care about jobs, and so politicians do. Or politicians might expect positive spillover effects or tax revenue from the presence of multinational companies. But politicians are also interested in general welfare, partly because they are benevolent, partly because they intend to improve their chance of reelection. Moreover, they might be interested in contribution payments. These can be used for election campaigns, personal joy, or may be stuffed into anonymous bank accounts for harder times. This analysis relies on a different aspect of multinational firms. Multinationals can relocate production at lower costs than national firms. I will determine how this aspect affects national regulation, if the politician cares about aggregate welfare and contribution payments.

This section analyzes these issues in a two stage game. ${ }^{19}$ The game is solved backwards. In the first stage, the firm decides about an optimal contribution schedule offered to the politician, $C^{*}(r)$. The contribution schedule is a menu,

\footnotetext{
${ }^{19}$ The approach follows Bernheim and Whinston (1986) and Grossman and Helpman (1994). Grossman and Helpman (2001) and Polk (2002) provide comprehensive surveys about this and other approaches towards lobbying.
} 
which maps regulation into money payments to the politician. The firm decides about the contribution schedule and takes the politician's behavior into account. In the second stage of the game, the politician observes these offers and decides about the optimal amount of regulation, $r^{*}$. Hence $\left[C^{*}(r), r^{*}\right]$ determines the political equilibrium. Money payments are made, dependent on the offered contribution schedule and the resulting choice of regulation. ${ }^{20}$

I take the result of the previous section as a starting point. Proposition 1 states conditions such that a multinational has smaller stakes in the home market with sufficiently high regulation, compared to a national firm. Corollary 2 applies the general result to a specific form of Cournot competition. It derives critical values for the regulation parameter and transportation costs, such that a multinational has smaller stakes in the home country compared to a national firm (compare also figure 4). In both cases, if regulation is sufficiently low, both types of firms have the same stakes in the domestic market. The focus of this section lies on differences between multinational and national firms. Therefore, I restrict the analysis to parameter ranges such that both types of firms have different stakes in national regulation, i.e.

$$
\frac{\partial \Pi^{N A T}(r, s)}{\partial r}<\frac{\partial \Pi^{M N E}(r, s)}{\partial r}
$$

holds.

Aggregate welfare depends on the net benefit of regulation, $B(r)$, and the amount of goods produced and consumed in the home country, $q^{S}(r)$ and $q^{D}(r)$. The net benefit of regulation might be interpreted as reduced environmental damage, higher labor standards, or welfare gains through a higher degree of competition. The distinction between goods consumed and goods produced reflects the idea that the politician cares about production in the home country and about consumers' well being. A good consumed in the home country increases welfare, but even more if it has been produced there. Hence, aggregate welfare is a linear function given as

$$
W(r)=W\left[B(r) ; q^{S}(r) ; q^{D}(r)\right] .
$$

Direct effects are assumed to be positive, i.e.

$$
\frac{\partial W}{\partial B}>0, \frac{\partial W}{\partial q^{S}}>0 \text { and } \quad \frac{\partial W}{\partial q^{D}}>0 .
$$

Regulation has a negative impact on the amount of goods produced and consumed in the home country, because regulation increases costs:

$$
\frac{\partial q^{S}}{\partial r}<0 ; \frac{\partial q^{D}}{\partial r}<0
$$

\footnotetext{
${ }^{20}$ Cheating is not possible, and money offers are paid as soon as the respective regulation is realized.
} 
Note that these assumptions are valid for many specific forms of competition. Moreover, I make the following assumption on the benefits of regulation:

Assumption 5 The benefit function $B(r)$ is concave, has a unique maximum, and $r^{b}=\arg \max _{r} B(r)$.

I make the two following assumptions, which state that a multinational and a national firm react differently if regulation increases. Both reduce production; however, the multinational can escape national regulation, since it is able to relocate production to the foreign country and thus escape national regulation at least partially. In contrast, the national firm is bound to produce in the home country. Hence, the effect of regulation on domestic production should be higher if the firm is a multinational. But relocation has also a positive effect on consumption in the home country. The multinational escapes national regulation, and costs rise to a smaller extent compared to a national firm. ${ }^{21}$ Hence, the effect of regulation on consumption is negative for both types of firms, and it is stronger if the firm is national.

Assumption 6 (relocation effect): The negative effect of regulation on production in the home country is stronger if the firm is a multinational:

$$
\left.\frac{\partial q^{S}}{\partial r}\right|_{M N E}<\left.\frac{\partial q^{S}}{\partial r}\right|_{N A T}<0 .
$$

Assumption 7 (consumption effect): The negative effect of regulation on consumption is weaker if the firm is a multinational:

$$
\left.\frac{\partial q^{D}}{\partial r}\right|_{N A T}<\left.\frac{\partial q^{D}}{\partial r}\right|_{M N E}<0 .
$$

Consider now the second stage of the game. A rational politician decides about regulation. He cares about aggregate welfare and contributions. Contribution offers result from firms' optimization in the first stage of the game. The politician takes these offers as given and decides about regulation. Thus in the second stage of the game, the politician chooses $r$ to maximize his payoff, given the contribution schedule $C(r)$ :

$$
\max _{r} U(r)=W\left[B(r) ; q^{S}(r) ; q^{D}(r)\right]+\alpha C(r) .
$$

The firm is either a national or a multinational company, and I compare political outcomes with both types of firms. $\alpha \geq 0$ is a weight which specifies the

\footnotetext{
${ }^{21}$ Recall that the firm bears increased transportation costs to serve the home market. The total effect is positive, because otherwise relocation is not optimal.
} 
impact of money to the politician's payoff. Note that the politician's payoff function is separable in aggregate welfare and contribution payments. This is a common assumption, which assures that no interaction between contribution payments and aggregate welfare exist. ${ }^{22}$

The optimal amount of regulation, $r^{*}$, is determined by the following first order condition:

$$
\frac{\partial W(r)}{\partial r}+\alpha \frac{\partial C(r)}{\partial r}=0
$$

As a special case, consider a benevolent politician who does not care for contributions, i.e. $\alpha=0$. In this case, the politician maximizes aggregate welfare and chooses $r^{0}=\operatorname{argmax} W(r)$. By observation of the first order condition, the following insights result: The marginal (net) benefit of regulation is positive in equilibrium, because the politician trades-off net benefits from regulation with negative effects on consumption and production. This results in regulation $r^{0}<r^{b}$. If the politician cares about contributions, political costs of regulation change. They may increase or decrease, which depends on the effect of regulation on contribution payments. Note that I cannot specify this function at the moment, because it depends on the firm's optimization in the first stage of the game. Suppose that it turns out that contributions decrease in $r$. In this case, regulation decreases if the politician cares for contributions, i.e. $r^{*}<r^{0}<r^{b}$. Lower regulation results and aggregate welfare declines. If contributions increase in $r$, regulation with lobbying will be higher than the welfare maximizing level, i.e. $r^{*}>r^{0}$. It may even be higher than $r^{b}$, which is the maximum of the benefit function. I will restrict my attention to decreasing contribution schedules in the following. This is natural to do so, because the following arguments show that contribution offers can only increase if the lobbying firm has an interest in high regulation. This is never the case if the firm produces at least partly in the home country. It may only result if the multinational completely relocates and benefits from high domestic regulation through a raising rivals' costs argument. I will exclude this special case in the following, but indicate here that it may arise in general. ${ }^{23}$

Consider now the first stage of the game. The firm anticipates the behavior of the politician. It realizes that in order to induce a deviation from $r^{0}$ towards

\footnotetext{
${ }^{22}$ To be more precise, separability assures that income is transferable without loss. The marginal utility of income is constant at rate $\alpha$, and is independent of the level of aggregate utility. To illustrate this point, consider a payoff function of the form $U=U[W(r), C(r)]$, and $U$ concave in $W$ and $C$. In this case, the marginal utility of contributions decreases in $C$. Moreover, it may also depend on the total level of aggregate welfare, because this specification allows that $\frac{\partial^{2} U}{\partial C \partial W} \neq 0$.

${ }^{23}$ Some countries prohibit lobbying activities by foreign firms, as for instance the United States.
} 
any alternative regulation, the contribution schedule must locally satisfy the politician's first order condition around the preferred level of regulation. If this was not the case, the politician would not deviate in the second stage of the game facing the respective contribution schedule. Thus, in order to induce a policy deviation towards any regulation, the contribution schedule must satisfy the following condition in the neighborhood of $r$ :

$$
\frac{\partial C(r)}{\partial r}=-\frac{1}{\alpha} \frac{\partial W(r)}{\partial r}
$$

Integration yields

$$
C(r)=-\frac{1}{\alpha} W(r)+x .
$$

Thus, any contribution schedule which shall be suitable to induce a certain regulation policy $r$ must satisfy the stated form locally. This is a necessary condition for the contribution schedule. Note that contribution payments for a deviation towards a particular regulation depend on the induced level of aggregate welfare, the weight $\alpha$, and a fixed parameter $x$, which shifts the contribution schedule vertically and will be discussed in the following.

To understand what determines $x$, we have to take the maximization problem of the firm into account. The firm maximizes net profits, which are variable profits minus contribution payments, $\Pi(r, s)-C(r) .{ }^{24}$ Note that the firm determines a complete menu offer, which consists of contribution offers for all possible regulations. This is a complete function $C(r)$, which is more than the contribution payment for the equilibrium policy choice $r^{*}$. The firm has to take three constraints into account: First, any contribution schedule which induces a deviation from $r^{0}$ must satisfy the above form locally at the realized level of regulation. Otherwise it would not induce the proper behavior of the politician in the second stage of the game. Second, to induce a political outcome different from $r^{0}$, the contribution payment needs to compensate the politician for the deviation from his welfare maximizing policy $r^{0}$. Hence, the firm must consider the politician's participation constraint, which is $W(r)+\alpha C(r) \geq W\left(r^{0}\right)$. Third, it is optimal to offer positive payments only for certain policies if the resulting net profits including contribution payments exceed profits which are realized if no contributions occur and $r^{0}$ results, $\Pi\left(r^{0}, s\right)$. Hence contributions are positive for any regulation $r$ only if $\Pi(r, s)-C(r) \geq \Pi\left(r^{0}, s\right)$.

The firm solves

$$
\begin{array}{lll}
\max _{C(r)} \Pi(r, s)-C(r) \quad \text { s.t. } & C(r)=-\frac{1}{\alpha} W(r)+x \\
& W(r)+\alpha C(r) \geq W\left(r^{0}\right) \\
& \Pi(r, s)-C(r) \geq \Pi\left(r^{0}, s\right) .
\end{array}
$$

\footnotetext{
${ }^{24}$ With slight abuse of notation, I drop the suffixes for firm types. The assumptions hold for both types in the same way.
} 
Note that $x$ is a parameter which shifts profits to the politician on account of the firm. If $x$ is high, higher contribution payments are made in exchange for a policy deviation. Hence the firm has an interest to choose $x$ as low as possible, but high enough to induce the preferred policy outcome. From the first and second constraint of the firm maximization problem follows

$$
x \geq \frac{1}{\alpha} W\left(r^{0}\right) .
$$

Hence any contribution schedule satisfying

$$
C(r) \geq \frac{1}{\alpha}\left[W\left(r^{0}\right)-W(r)\right]
$$

is suitable to induce a policy deviation from $r^{0}$. Moreover, the firm will always choose the smallest amount of contribution payments which are sufficient to induce a certain policy deviation from $r^{0}$, because contribution payments are not costless. Thus the equation must be binding in order to maximize profits, and any contribution schedule which entails higher payments for all levels of regulation can not optimal: The firm could always increase profits through a slight reduction of $x$ in this case, without affecting the policy outcome.

Hence, if the firm anticipates how the politician decides in the second stage of the game, it realizes that any policy $r$ is feasible through a contribution schedule satisfying

$$
C(r)=\frac{1}{\alpha}\left[W\left(r^{0}\right)-W(r)\right]
$$

in the neighborhood of $r$. Intuitively, contribution payments compensate the politician for a policy deviation from $r^{0}$, which exactly offsets his induced utility decline. As a consequence, he is indifferent between the welfare maximizing policy $r^{0}$ and any alternative induced through this contribution offer. Note that the firm benefits from a first mover advantage. It anticipates how the politician reacts towards any possible contribution schedule $C(r)$ and minimizes compensation payments given that they are suitable to induce the preferred policy outcome, and it realizes the full rent from the political interaction.

Note that it is not optimal to offer positive compensation payments according to the above equation to any $r$, because this may violate the participation constraint of the firm. Hence the firm prefers to pay zero contributions for any policy deviation which necessitates compensation payments exceeding the benefit from deviation, and an optimal contribution schedule satisfies $C(r)=0$ for any $r$ satisfying $\Pi(r, s)-\frac{1}{\alpha}\left[W\left(r^{0}\right)-W(r)\right] \leq \Pi\left(r^{0}, s\right) .{ }^{25}$

\footnotetext{
${ }^{25}$ To be more precise, zero contribution offers are not necessary. It suffices that they are small enough to not affect the policy outcome (compare the appendix).
} 
Consider the following contribution schedule as a suggestion for the solution to the maximization problem:

$$
C(r)= \begin{cases}0 & \text {, if } \Pi(r, s)-\frac{1}{\alpha}\left[W\left(r^{0}\right)-W(r)\right] \leq \Pi\left(r^{0}, s\right) \\ \frac{1}{\alpha}\left[W\left(r^{0}\right)-W(r)\right] & \text {, if } \Pi(r, s)-\frac{1}{\alpha}\left[W\left(r^{0}\right)-W(r)\right]>\Pi\left(r^{0}, s\right) .\end{cases}
$$

This contribution schedule satisfies all conditions of the maximization problem. Contribution payments are positive only if the profit increase through the induced policy deviation exceeds the contribution payments which are necessary to induce this outcome; otherwise they equal zero. The firm exactly compensates the politician for the respective policy deviation from $r^{0}$ if contribution payments are positive. Note that this contribution schedule has an interesting property: Since any positive contribution payment exactly compensates the politician for the policy deviation, he remains indifferent between the welfare maximizing regulation $r^{0}$, and any deviation associated with positive contribution payments.

In fact, the firm is able to induce its most preferred policy outcome through a slight modification of the above contribution schedule. This is an implication of the first mover advantage: Anticipating the politician's behavior, the firm is able to induce its preferred policy through the choice of a suitable contribution schedule as long as the contribution function satisfies the stated constraints.

The optimal policy choice $r^{*}$, given that the firm compensates the politician for the deviation, is given by the first order condition of the firm. Hence

$$
r^{*}=\operatorname{argmax}_{r} \Pi(r, s)-\frac{1}{\alpha}\left[W\left(r^{0}\right)-W(r)\right],
$$

This result states that the firm prefers a policy choice whose marginal benefit exactly offsets the marginal costs which are necessary to achieve it. This allows us to determine the optimal contribution schedule. To be precise, there is an infinite number of optimal contribution schedules $C^{*}(r)$ which implements the most preferred outcome: The reason is as follows: The firm must compensate the politician for the policy deviation towards $r^{*}$, as characterized above. Contribution offers must be zero for all policy variables satisfying $\Pi(r, s)-\frac{1}{\alpha}\left[W\left(r^{0}\right)-W(r)\right] \leq \Pi\left(r^{0}, s\right)$. But the contribution offers distinct from $C^{*}\left(r^{*}\right)$ and not satisfying this latter condition are arbitrary as long as they induce no other policy deviation. I restrict attention to one particular form: ${ }^{26}$

\footnotetext{
${ }^{26}$ The complete specification of all optimal contribution schedules is given in the appendix. The form stated here satisfies the "natural" refinement of Kirchsteiger and Prat (2002).
} 
Lemma 1 The following contribution schedule solves the maximization problem of the firm:

$$
C^{*}(r)= \begin{cases}0 & , \text { if } r \neq r^{*} \\ \frac{1}{\alpha}\left[W\left(r^{0}\right)-W(r)\right] & , \text { if } r=r^{*}\end{cases}
$$

This particular contribution schedule is optimal for the firm. It offers a compensation payment for a policy deviation towards $r^{*}$, which leaves the politician indifferent between the welfare maximizing policy $r^{0}$ and the most preferred policy of the firm. ${ }^{27}$ Contribution offers for all other policies are zero. Hence the contribution schedule induces a policy deviation towards $r^{*}$, which is the best policy choice of the firm. Note that zero contribution offers result for two reasons: Some contribution offers are zero, because the firm realizes that it cannot induce the respective policy deviation and gain something. Hence it offers nothing. In contrast, some policy deviations are feasible for the firm, because necessary compensation payments are smaller compared to the resulting benefit. But although feasible generally, it is not optimal to induce them because they do not maximize firm's profits net of contribution payments. Hence the firm can offer zero contributions for these policy choices as well.

The form of the optimal contribution schedule is the same for a multinational and a national firm for a broad range of $r$. Both firms pay positive contributions which are sufficient to compensate the politician for a policy deviation towards its most preferred policy choice. But the contribution schedules differ with respect to four aspects: First, the intervals of feasible policy deviations differ between both types of firm, because they depend on $\Pi(r, s)$ and $\Pi\left(r^{0}, s\right)$ which are different for the multinational and the national firm. Second, $r^{0}$ differs in both cases: The politician chooses a different regulation policy without lobbying, which depends on the present type of firm. Third, equilibrium contribution payments compensate the politician for a deviation from $r^{0}$. These compensations depend on the loss in aggregate welfare if regulation decreases. Welfare depends on the amount of goods which are produced and consumed in the home country, and these amounts change differently for both types of firms (assumptions 6 and 7). Finally, the optimal policy choice $r^{*}$ may differ between a national and a multinational firm.

Note that equilibrium contribution payments tend to be high if the politician cares much about welfare. In this case $\alpha$ is small, and the firm must offer high compensation payments to induce a policy deviation. As a result, firm's payoff decreases if the politician cares much about aggregate welfare, and more money is transferred on behalf of the politician. The politician's payoff is independent

\footnotetext{
${ }^{27} \mathrm{I}$ assume that the politician deviates if he is indifferent. Otherwise the firm could increase the contribution payment for $r^{*}$ by a small amount, and the politician would be strictly better off with deviation.
} 
of $\alpha$, because he gets exactly compensated for the equilibrium policy deviation. For instance, if he cares much about aggregate welfare contribution payments tend to be high in equilibrium, but his marginal benefit of money is small in this case.

This result can be used to solve the model completely. The firm determines the optimal contribution schedule $C^{*}(r)$ in the first stage of the game. It anticipates the politician's behavior of the second stage and induces a certain policy outcome, $r^{*}$. Thus $\left[C^{*}(r), r^{*}\right]$ determines the political equilibrium. ${ }^{28}$ This leads to the following proposition:

Proposition 3 The multinational company tends to face lower regulation compared to a national firm, if the following conditions hold:

- The consumption effect is relatively unimportant, or consumption has only small welfare effects.

- The multinational and the national firm do not differ much with respect to their stakes in national regulation.

The multinational tends to face higher regulation compared to a national firm, if the following condition holds:

- The relocation effect is small if the firm is a multinational, or production is unimportant for aggregate welfare.

Proof. The proof is given in the appendix.

By assumption, regulation has a positive direct effect on aggregate welfare and negative effects on consumption and production in the home country. The relocation effect tends to lower regulation if the firm is a multinational, because regulation affects national production to a greater extent in this case. Hence, if the politician cares much about production in the home country and the relocation effect is large, regulation might favor the interests of the multinational company. The consumption effect works in the opposite direction. The multinational company is able to escape national regulation at least partially and the negative effect on domestic consumption is smaller in this case. This effect tends towards higher regulation of multinational companies.

The proposition also covers the first part of the analysis: Both types of firms may have different stakes in domestic regulation, which depends on exogenous parameters as described in section 3. In this case, a national firm is c.p.

\footnotetext{
${ }^{28}$ Note that an infinite amount of equilibria exists, because an infinite number of optimal contribution schedules induce the optimal policy deviation $r^{*}$.
} 
willing to offer higher contribution payments at the margin, because national regulation affects it to a greater extent. As a result, regulation tends to be lower if national firms are present compared to multinationals. With only small stakes in the home market, multinationals' incentives to engage in lobbying are small. The extent of this effect depends on the marginal benefit of contribution payments. If the politician cares much about contributions, the tendency towards lower regulation of national firms increases.

The model predicts that the existence of multinational firms has ambiguous effects on national regulation, which raises scepticism about the common perception that the presence of multinational companies leads to a loss of sovereignty of the national state. In this setup, rather strict conditions must be fulfilled to support this view. However, it may well be valid if relocation is very important. Which view is suitable comes down to an empirical test of the relative strength of these effects. If it turns out that politicians have a high interest in local production and relocation is an important issue, the model may support the common perception. If this is not the case, multinationals tend to face higher regulation than national firms, and the presence of these firms does not reduce the scope of national policy making.

\section{Discussion and conclusions}

The approach provides a formal analysis how differences in lobbying incentives between a multinational and a national firm affect the political outcome. It is independent of specific market forms or the type of competition. A multinational differs from a national firm because it has smaller costs of relocating production. Smaller stakes in the national market result, and a multinational can always perform at least as good as a national firm. National regulation tends to have smaller impacts on multinationals, which tends to decrease their lobbying incentives. Less influence on the political decision can then be expected. This argument suggests that multinationals tend to face higher regulation than national firms. In addition, consumer surplus declines less in the home country if regulation affects multinationals. These two effects, the lobbying effect and the consumption effect, tend towards an outcome of the lobbying game which neglects the common perception that multinationals reduce the scope of national politics.

An effect which works in favor of less regulation of multinational firms is the production effect. Multinationals may relocate production due to unwanted regulation, which decreases local production to a higher extent compared to national firms. If politicians are interested in domestic production, they might be hesitant to introduce high regulation in order to avoid a drain of capital. If 
this effect is strong, the presence of multinational companies may well lead to a loss of sovereignty of the nation state.

The paper provides some hypothesis for empirical investigation. Less regulation of multinationals should coincide with the importance of local production to politicians. Moreover, regulation should be lax in sectors with relatively footloose capital, compared to sectors where relocation is costly. Regulation of multinationals should be lax if lobbying is not too important, or the politician cares not much about contribution payments. For instance, a politician might have less discretion to set policies in sectors facing much public attention. In contrast, it might be easier to cater to special interests in sectors attracting little public attention, and contributions might be of higher importance then.

Let me finally discuss two possible extensions. First, we can relax the assumption that only one firm is present in the market. I conjecture that the extension to several domestic and multinational firms does not affect the main insights. The fact that the possibility to relocate production induces differences in lobbying incentives does not depend on the number of politically active firms. However, such an extension would allow to analyze incentives to free-ride on other firms and may be worthy of consideration in future research. Second, politicians and multinationals might have asymmetric information about the possible extent of relocation. A multinational might be better informed about its production and costs structure than the politician. I expect that regulation works more in favor of the multinational in this case. 


\section{Appendix}

\section{Proof of Proposition 1:}

A necessary and sufficient condition that the firm relocates at some level of regulation is given, if it is optimal to relocate at least partially if the regulation takes on its tightest form. These conditions are given by

$\max \left\{\Pi^{p r}(\bar{r}, s)-F^{p r} ; \Pi^{c r}(\bar{r}, s)-F^{c r}\right\}>\Pi^{n r}(\bar{r}, s)$.

This can be rewritten as in condition (i).

Next one has to assure that a regulation exists such that it is optimal to produce in the home market only. Profits not only decrease in regulation (assumption 2), but even faster if production takes place in the home country only (assumption 3). Thus it is necessary and sufficient to check whether it is optimal to produce in the home market if regulation takes on its minimum level. This condition is given by

$\Pi^{n r}(0, s)>\max \left\{\Pi^{p r}(0, s)-F^{p r} ; \Pi^{c r}(0, s)-F^{c r}\right\}$.

Denote $F_{c r i t}^{p r}(r)$ as the critical level of fixed costs which makes the firm indifferent between moving partially and staying in the home country if regulation is $r$. Thus $F_{c r i t}^{p r}(r) \equiv \Pi^{p r}(r, s)-\Pi^{n r}(r, s)$. Differentiating yields that this critical value is increasing in $r$ by assumptions 2 and 3. Analogously, $F_{c r i t}^{c r}(r) \equiv \Pi^{c r}(r, s)-\Pi^{n r}(r, s)$ is increasing in r. By comparing these critical values, one gets that fixed moving costs increase faster in $\mathrm{r}$ in the case of complete relocation (again by assumption 3). Thus the relevant assumption must be $\Pi^{n r}(0, s)>\Pi^{p r}(0, s)-F^{p r}$, as stated in part (ii) of the proposition.

\section{Proof of Proposition 2:}

Using standard technique one can derive the quantities sold by each firm in each market for every possible production structure of the multinational. By assumption 1, each of these quantities must be positive. This gives assumptions on the relationship between the demand parameter a, marginal cost of production $\mathrm{m}$, transportation costs $s$ and the tax $t$. These assumptions are satisfied if $a-m \geq 2(s+t)$ holds.

Straight forward application of standard oligopoly theory then yields the following profit functions for the multinational:

$$
\begin{aligned}
& \Pi^{n r}(s, t)=\frac{1}{9}\left[(a-m+s-2 t)^{2}+(a-m-2 s-2 t)^{2}\right], \\
& \Pi^{p r}(s, t)=\frac{1}{9}\left[(a-m+s-2 t)^{2}+(a-m)^{2}\right]-F, \\
& \Pi^{c r}(s, t)=\frac{1}{9}\left[(a-m-s)^{2}+(a-m)^{2}\right]-F .
\end{aligned}
$$

Taking derivatives, it is easy to check that assumptions 2 and 3 are satisfied. Thus all assumptions are satisfied. 
Part (i) of proposition 1 gives an upper bound for the fixed cost parameter $F$. Simply plug $t^{\max }=\frac{1}{2}(a-m)-s$ into the profit functions and compare. This give the upper bound which is stated in part (iii) of proposition 2 .

Part (ii) of proposition 1 gives a lower bound for $F$. Set $t=0$ and compare profits without relocation and with partial relocation. This gives the lower bound, which is stated in part (iii) of proposition 2 .

Hence the conditions stated in proposition 2 assure that all assumptions of proposition 1 are satisfied and the result follows.

\section{Proof of Corollary 2:}

We know that the firm produces in the home country only, if the tax is small.

The case of high transportation costs

If $\Pi^{p r}\left(s, t^{\max }\right)>\Pi^{c r}\left(s, t^{\max }\right)$, it can never be optimal to relocate completely for any value of $t$. Plug in the value of $t^{\max }$ and see that this is the case if $s>\frac{1}{4}(a-m)$, which is the critical value $s^{*}$. The critical value of the tax where relocation is pays is given by $t^{1}$.

\section{The case of low transportation costs}

By the former result, complete relocation pays for some tax level if $s<s^{*}$. It has to be clarified if partial relocation is optimal for some interval on $t$, or not. This can be done by comparing the values of the profit functions at $t=t^{1}$.

If $\Pi^{p r}\left(s, t^{1}\right)>\Pi^{c r}\left(s, t^{1}\right)$, profits are higher at $t^{1}$ if the firm does not relocate completely, but only partially to the foreign country. This condition yields $\left(s-t^{1}\right)\left(a-m-t^{1}\right)>0$, which is equivalent to $s>t^{1}$. We know that complete relocation is optimal if the tax is high enough. Thus to determine the relevant critical value, one has to find the value of the tax such that the firm is indifferent between partial and complete relocation. This yields $t=s$ as the critical value and completes the proof if $t^{1}<s<s^{*}$.

For the case of $s<s^{*}$ and $s<t^{1}$, the proof is analogous. If $\Pi^{p r}\left(s, t^{1}\right)<$ $\Pi^{c r}\left(s, t^{1}\right)$, production in both countries is not optimal if $t=t^{1}$. Thus a smaller level $t^{2}$ must exist, such that immediate complete relocation is optimal. This value is determined by comparing $\Pi^{p r}(s, t)$ and $\Pi^{c r}(s, t)$, which yields the respective value for $t^{2}$.

\section{Complete specification of the optimal contribution schedule:}

There is an infinite number of optimal contribution schedules which satisfy the stated conditions. Remember that

$$
r^{*}=\operatorname{argmax}_{r} \Pi(r, s)-\frac{1}{\alpha}\left[W\left(r^{0}\right)-W(r)\right] .
$$


All contribution schedules of the following form are optimal:

$$
C^{*}(r)=\left\{\begin{array}{lll}
\frac{1}{\alpha}\left[W\left(r^{0}\right)-W(r)\right] & , \text { if } & r=r^{*} \\
\frac{1}{\alpha}\left[W\left(r^{0}\right)-W(r)\right]-\epsilon(r) & , \text { if } & r \neq r^{*}
\end{array}\right.
$$

The function $\epsilon(r)$ is an element of a class of functions satisfying

- $\epsilon(r)>0$, and

- $\epsilon(r) \leq \frac{1}{\alpha}\left[W\left(r^{0}\right)-W(r)\right]$.

\section{Proof of Proposition 3:}

We know that the politicians chooses $r^{*}$ in the second stage of the game, given $C^{*}(r)$. Hence in equilibrium

$$
\frac{\partial C(r)}{\partial r}=-\frac{1}{\alpha} \frac{\partial W(r)}{\partial r} .
$$

Note that I assume differentiability of the contribution function around $r^{*}$ here, which is slightly imprecise with respect to the stated contribution schedule of lemma 1. From the preceding discussion, continuous contribution function around $r^{*}$ are easy to find. Hence I ignore this slight imprecision here.

We also know that this induces the optimal policy choice of the firm, $r^{*}$. By the first order condition of the firm, we get

$$
\frac{\partial \Pi(r, s)}{\partial r}=-\frac{1}{\alpha}\left[\frac{\partial W}{\partial B} \frac{\partial B(r)}{\partial r}+\frac{\partial W}{\partial q^{S}} \frac{\partial q^{S}(r)}{\partial r}+\frac{\partial W}{\partial q^{D}} \frac{\partial q^{D}(r)}{\partial r}\right]
$$

around the equilibrium. The result follows from comparison of this first order condition if the firm is national or a multinational. 


\section{References}

Bernheim, B. Douglas and Michael D. Whinston (1986). Menu Auctions, Resource Allocation, And Economic Influence. Quarterly Journal of Economics, 51(1):1-31.

Bhagwati, Jagdish N., Elias Dinopoulos and Kar yiu Won (1987). Quid Pro Quo Foreign Investment and Welfare: A Political-Economy-Theoretic Model. Journal of Development Economics, 27(1-2):127-38.

Bhagwati, Jagdish N., Elias Dinopoulos and Kar yiu Wong (1992). Quid Pro Quo Foreign Investment. American Economic Review, 82(2):186-90.

Blonigen, Bruce A. and Yuka Ohno (1998). Endogenous Protection, Foreign Direct Investment and Protection-Building Trade. Journal of International Economics, 46(2):205-27.

Ellingsen, Tore and Karl Warneryd (1999). Foreign Direct Investment and the Political Economy of Protection. International Economic Review, 40(2):357-79.

Grossman, Gene M. and Elhanan Helpman (1994). Protection for Sale. American Economic Review, 84(4):833-850.

- (1996). Foreign Investment with Endogenous Protection. In Robert C. Feenstra, GeneM. Grossman and Douglas A. Irwin, eds., The political economy of trade policy: Papers in honor of Jagdish Bhagwati, 199-223. Cambridge University Press.

— (2001). Special Interest Politics. The MIT Press, Cambridge, Mass. London.

Hillman, Arye L. and Heinrich W. Ursprung (1993). Multinational Firms, Political Competition, and International Trade Policy. International Economic Review, 34(2):347-63.

- (1999). Foreign Investment and Endogenous Protection with Protectionist Quid Pro Quo. Economics and Politics, 11(1):1-12.

Hirschman, Albert O., ed. (1970). Exit, Voice and Loyalty. Harvard University Press.

Janeba, Eckhard (2000). Tax Competition When Governments Lack Commitment: Excess Capacity as a Countervailing Threat. American Economic Review, 90(5):1508-19. 
Kirchsteiger, Georg and Andrea Prat (2002). Inefficient Equilibria in Lobbying. Journal of Public Economics, forthcoming.

Konishi, Hideo, Kamal Saggi and Shlomo Weber (1999). Endogenous Trade Policy under Foreign Direst Investment. Journal of International Economics, 49(2):289-308.

OECD (1999). Recent Trends in Foreign Direct Investment. Financial Market Trends, 72(1):109-126.

Olarreaga, M. (1999). Foreign-Owned Capital and Endogenous Tariffs. World Bank Working Paper.

Polk, Andreas (2002). How Special Interests Shape Policy - A Survey. Working Paper of the Socioeconomic Institute. University of Zurich.

Porter, Michael E. (1991). America's Green Strategy. Scientific American, 264:168.

Porter, Michael E. and Claas van der Linde (1995). Toward a New Conception of the Environment-Competitiveness Relationship. Journal of Economic Perspectives, 9(4):97-118.

Rauscher, M. (1995). Environmental Regulation and the location of Polluting Industries. International Tax and Public Finance, 2(2):229-244.

Reich, Robert (1993). The Work Of Nations. Harvard University Press, Cambridge, Mass.

Schmutzler, Armin (2001). Environmental Regulations and Managerial Myopia. Environmental and Resource Economics, 18(1):87-100.

Summers, Lawrence H. (1999). Distinguished Lecture on Economics in Government: Reflections on Managing Global Integration. Journal of Economic Perspectives, 13(2):3-18.

UNCTAD (2001). World Investment Report. United Nations, Genf - New York. 
The Working Papers of the Socioeconomic Institute can be downloaded in from http:/www.soi.unizh.ch/research/wp/index2.html

$0205 \quad$ Lobbying Activities of Multinational Firms

Andreas Polk, 2002, 32 p.

0204 Subjective Well-being and the Family

Rainer Winkelmann, 2002, 18 p.

$0203 \quad$ Work and health in Switzerland: Immigrants and Natives

Rainer Winkelmann, 2002, 27 p.

0202 Why do firms recruit internationally? Results from the IZA International Employer Survey 2000

Rainer Winkelmann, 2002, 25 p.

0201 Multilateral Agreement On Investments (MAI) - A Critical Assessment From An Industrial Economics Point Of View

Andreas Polk, 2002, 25 p.

0103 Finanzintermediäre Grössennachteile und Spezialisierungsvorteile Michael Breuer, 2001, 31 p.

$0102 \quad$ How to Regulate Vertical Market Structure in Network Industries Stefan Buehler, 2001, 35 p.

0101 Empirische Analyse des Zeitpunktes schweizerischer Direktinvestitionen in Osteuropa Markus König, 2001, 26 p.

$0003 \quad$ Measuring Willingness-To-Pay for Risk Reduction: An Application of Conjoint Analysis Harry Telser, Peter Zweifel, 2000, 21 p.

0002 Quality Provision in Deregulated Industries: The Railtrack Problem M.A. Benz, S. Bühler, A. Schmutzler, 2000, 32 p.

0001 Is Swiss Telecommunications a Natural Monopoly? An Evaluation of Empirical Evidence Stefan Bühler, 2000, 23 p.

9906 Innovation and the Emergence of Market Dominance, Susan Athey and Armin Schmutzler, 1999, 42 p.

$9905 \quad$ Multilaterale Investitionsabkommen - Lernen aus dem MAI? Andreas Polk, 1999, 32 p. 